\title{
KONTROLA A TESTOVANIE NIVELAČNÝCH PRÍSTROJ OV PRE PRÁCE V STAVEBNÍCTVE
}

\author{
VERIFICATION AND TESTING OF LEVELING INSTRUMENTS FOR WORK IN \\ BUILDING INDUSTRY
}

Ing. J ežko J án. Ph.D.

\begin{abstract}
ABSTRAKT
Príspevok predstavuje postup testovania nivelačných prístrojov využívaných pri prácach v stavebníctve. Všeobecne popísaný postup testovania a overovania nivelačných prístrojov (optických i digitálnych) je doplnený výsledkami a hodnotením štyroch vybraných nivelačných prístrojov (Sokkia C40, Geo Fennell NO.10, Spectra AL100 a Leica Sprinter 150) využívaných pre práce v stavebníctve v oblasti technickej nivelácie.
\end{abstract}

Klíčová slova: technická norma, nivelačný prístroj, technická nivelácia, zjednodušený a úplný postup.

\section{ABSTRACT}

The article introduces the testing procedure of levelling instruments in construction. Generally described testing and validation procedure of levelling instruments (optical and digital as well) is supplemented by results and evaluation of four selected levelling instruments (Sokkia C40, Geo Fennell NO.10, Spectra AL100 a Leica Sprinter 150) used to work in technical levelling.

Key words: technical standard, levelling instrument, technical levelling, simplified and complete procedure.

\section{1 ÚVOD}

Pri práci s nivelačnými prístrojmi (NP) sa predpokladá splnenie základných osových podmienok, definovaných pre tento typ geodetických prístrojov. NP však ako každé meracie prístroje podliehajú rôznym vplyvom, ktoré môžu spôsobit' nedostatočné presné určenie prevýšení. Ciel’om príspevku je výklad a aplikácia testovacieho postupu pre určenie odchýlky sklonu zámernej priamky a určenie presnosti prevýšenia meraného $v$ nivelačnej zostave podla technickéj normy STN ISO 17123-2 $\mathrm{s}$ aplikáciou pre štyri nivelačné prístroje.

\section{KONTROLA A TESTOV ANIE NIVELAČNÝCH PRÍSTROJOV}

Kontrola a testovanie geodetických prístrojov používaných v stavebnej praxi je možné realizovat' podla niektorých medzinárodných noriem. Do týchto noriem patrí aj STN ISO 17123-2 (Nivelačné prístroje). Norma je z oblasti pôsobnosti medzinárodnej technickej komisie ISO/TC 172/SC 6 „Optics and optical instruments /Geodetic and surveying instruments“ (Optika a optické prístroje/Geodetické a meracie prístroje). Špecifikuje skúšobné postupy, zamerané na určovanie a odhad presnosti nivelačných prístrojov a pomôcok pri meraniach v stavebníctve a geodézií. Ciel'om týchto skúšok je najmä overenie vhodnosti jednotlivých prístrojov na príslušnú úlohu a splnenie požiadaviek iných noriem. Skladá sa z dvoch častí - postupov $[1,4,5]$ :

- zjednodušená metodika testovania (vhodná pre prístroje používané v stavebnej praxi prístroje nižšej triedy presnosti),

- úplná metodika testovania (vhodná pre prístroje určené pre presnú niveláciu, aplikácie v inžinierskej geodézii - prístroje vyššej triedy presnosti). 


\subsection{Zjednodušená metodika testovania}

Metodika je určená na určovanie presnosti optických nivelačných prístrojov používaných na niveláciu a na úlohy v stavebnej praxi s možnost’ou používania nerovnakých dížok zámer. Postup je založený na určení prevýšenia medzi dvoma bodmi (60m vzdialenými), určuje či testovaný prístroj vyhovuje dovolenej odchýlke pre plánovanú meračskú úlohu $[1,2,3]$.

\subsection{Konfigurácia testovacej priamky}

Pre zníženie vplyvu refrakcie na minimum, je vhodné na realizáciu skúšky vybrat' vodorovné územie (obr. 1.1, 1.2, [3]).

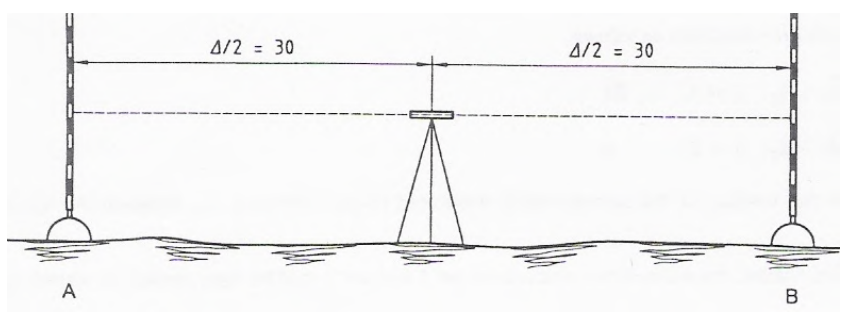

Obr. 1 (prevzaté z [3])

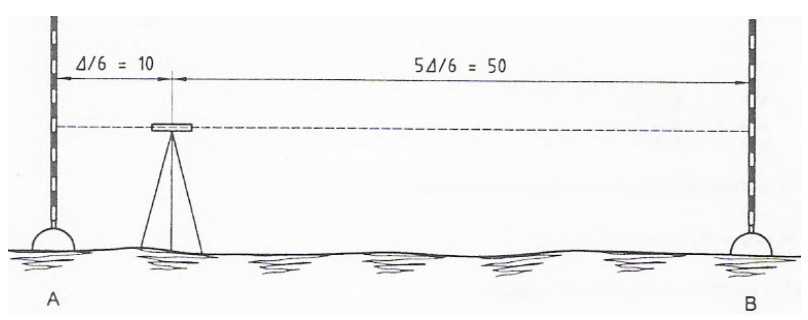

Obr. 2 (prevzaté z [3])

\subsection{Postup merania}

Pred meraním je potrebné prístroj aklimatizovat' s vonkajším prostredím $\left(2 \mathrm{~min}\right.$. na $1^{\circ} \mathrm{C}$ teplotného rozdielu). Potom sa vykonajú dve série meraní. V prvej sérii sa prístroj postaví približne do stredu medzi dva body A,B $(\Delta / 2=30 \mathrm{~m})$. Táto konfigurácia minimalizuje vplyv refrakcie a chyby optickej sústavy (obr. 1). Séria merania pozostáva z 10 meraní, každé meranie pozostáva z odčítania zámery $\operatorname{vzad} x_{A, j}$, na bode A a jedného odčítania vpred $x_{B, j}$, na bode $\mathrm{B}$. Medzi každým párom odčítaní je treba zmenit' mierne polohu prístroja a znovu urovnat' a odčítat' nové hodnoty. Po piatich meraniach $\left(x_{A l}\right.$, $\left.x_{B 1}, \ldots . . x_{A 5}, x_{B 5}\right)$ sa merania vzad a vpred vymenia pre d'alších pät' meraní $\left(x_{A 6}, x_{B 6}, \ldots . . x_{A 10}, x_{B 10}\right)$. $\mathrm{V}$ druhej sérii je potrebné prístroj postavit' približne v polohe $\Delta / 6=10 \mathrm{~m}$ od bodu A a $5 \Delta / 6=50 \mathrm{~m}$ od bodu B (obr. 2). Takto sa realizuje d'alších desat' meraní rovnakým postupom ako pri prvej sérii [3].

\section{ANALÝZA NAMERANÝCH ÚDAJOV}

Matematicko-štatistická analýza meraných údajov sa delí podl’a použitej metodiky testovania (zjednodušená, alebo úplná).

\subsection{Spracovanie výsledkov testovania pri zjednodušenej metodike}

Prevýšenie pri testovaní je určené vzt'ahom:

$$
h_{j}=x_{A, j}-x_{B, j} ; \quad j=1, \ldots \ldots 10
$$

kde $h_{j}$ je rozdiel medzi odčítaním vzad $x_{A, j}$ a odčítaním vpred $x_{B, j}$.

$$
\bar{h}_{1}=\frac{\sum_{j=1}^{10} h_{j}}{10},
$$


kde $\bar{h}_{1}$ je priemerná hodnota prevýšení $h_{j}$ prvej série meraní. Hodnota $\bar{h}_{1}$ je považovaná za skutočnú hodnotu prevýšenia medzi bodmi A a B.

$$
v_{j}=\bar{h}_{1}-h_{j} \quad j=1, \ldots, 10,
$$

kde $v_{j}$ je oprava príslušného meraného výškového rozdielu $h_{j}$ prvej série meraní.

Ako počtárska kontrola slúži suma opráv jednej série.

$$
\begin{aligned}
& \sum_{j=1}^{10} v_{j}=0 . \\
& s=\sqrt{\frac{\sum_{j=1}^{10} v_{j}^{2}}{n},}
\end{aligned}
$$

kde: $\quad \sum_{j=1}^{10} v_{j}^{2}$ je suma štvorcov opráv $v_{j}$ prvej série a $n=10-1=9$ je príslušný počet stupňov vol’nosti (počet nadbytočných meraní), $s$ je empirická chyba výškového rozdielu, získaná z prvej série meraní.

$$
\bar{h}_{2}=\frac{\sum_{j=11}^{20} h_{j}}{10},
$$

kde $\bar{h}_{2}$ je priemerná hodnota výškových rozdielov $h_{j}$ druhej série meraní. Rozdiel $\bar{h}_{1}-\bar{h}_{2}$ musí byt' v rámci povolenej odchýlky $p$ (napr. podl'a ISO 4463-1) pre plánovanú meračskú úlohu. Ak $p$ nie je dané, vtom prípade rozdiel musí spíňat' podmienku $\left|\bar{h}_{1}-\bar{h}_{2}\right|<2,5 . s$, kde $s$ je empirická stredná chyba vypočítaná podl'a rovnice (3.5).

Ak je rozdiel $\left|\bar{h}_{1}-\bar{h}_{2}\right|$ príliš vel'ký, indikuje to nespol'ahlivost' merania pri vel'kých dížkach zámer (50m), a z toho vyplývajúce z chyby z odčítania, refrakcie a chybu zámernej osi.

V takomto prípade je treba:

- skontrolovat' chyby zámernej osi podl'a užívatel'ského manuálu,

- zredukovat' maximálnu dížku zámer.

\section{TESTOVANIE NIVELAČNÝCH PRÍSTROJOV PRE TECHNICKÚ NIVELÁCIU PODL'A STN ISO 17123-2}

Predchádzajúci postup testovania a overovania nivelačných prístrojov (optických i digitálnych) bol aplikovaný pri testovaní štyroch nivelačných prístrojov (Sokkia C40, Geo Fennell NO.10, Spectra AL100 a Leica Sprinter 150) využívaných pre práce v TN v stavebnej praxi (obr. 3, 4, 5, 6).

\subsection{Nivelačný prístroj Sokkia C40}

Údaje získané z merania prístrojom Sokkia C40, ako aj vypočítané prevýšenia, priemerné prevýšenia a opravy sa nachádzajú v tab. $1[1,2]$.

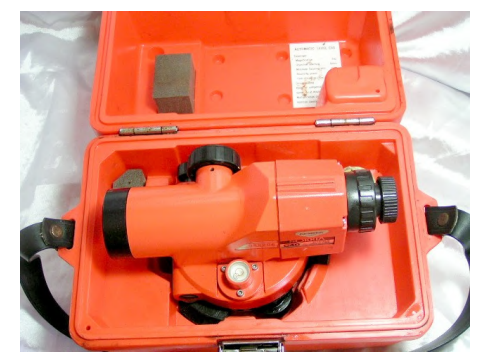

Obr. 3 Nivelačný prístroj Sokkia C40 [2]

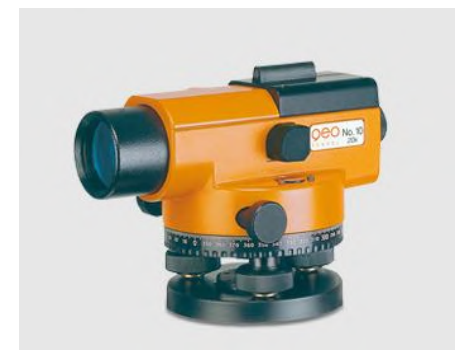

Obr. 4 Nivelačný prístroj Geo Fennell NO.10 [2] 


\begin{tabular}{|c|c|c|c|c|c|c|c|c|c|}
\hline 1 & 2 & 3 & 4 & 5 & 6 & 7 & 8 & 9 & 10 \\
$j$ & $\begin{array}{c}x_{A j} \\
{[\mathrm{~m}]}\end{array}$ & $\begin{array}{c}x_{B j} \\
{[\mathrm{~m}]}\end{array}$ & $\begin{array}{c}h_{j} \\
{[\mathrm{~m}]}\end{array}$ & $\begin{array}{c}v_{j} \\
{[\mathrm{~mm}]}\end{array}$ & $\begin{array}{c}v^{2}{ }_{j} \\
{\left[\mathrm{~mm}^{2}\right]}\end{array}$ & $j$ & $\begin{array}{c}x_{A j} \\
{[\mathrm{~m}]}\end{array}$ & $\begin{array}{c}x_{B j} \\
{[\mathrm{~m}]}\end{array}$ & $\begin{array}{c}h_{j} \\
{[\mathrm{~m}]}\end{array}$ \\
\hline 1 & 0,588 & 1,995 & $-1,407$ & $-2,0$ & 4,0 & 11 & 1,064 & 2,463 & $-1,399$ \\
\hline 2 & 0,612 & 2,009 & $-1,397$ & 8,0 & 64,0 & 12 & 1,034 & 2,442 & $-1,408$ \\
\hline 3 & 0,613 & 2,012 & $-1,399$ & 6,0 & 36,0 & 13 & 1,046 & 2,445 & $-1,399$ \\
\hline 4 & 0,576 & 1,983 & $-1,407$ & $-2,0$ & 4,0 & 14 & 1,042 & 2,441 & $-1,399$ \\
\hline 5 & 0,636 & 2,043 & $-1,407$ & $-2,0$ & 4,0 & 15 & 1,040 & 2,442 & $-1,402$ \\
\hline 6 & 2,022 & 0,615 & 1,407 & $-2,0$ & 4,0 & 16 & 2,443 & 1,043 & 1,400 \\
\hline 7 & 2,020 & 0,613 & 1,407 & $-2,0$ & 4,0 & 17 & 2,425 & 1,025 & 1,400 \\
\hline 8 & 2,000 & 0,593 & 1,407 & $-2,0$ & 4,0 & 18 & 2,449 & 1,039 & 1,410 \\
\hline 9 & 2,026 & 0,620 & 1,406 & $-1,0$ & 1,0 & 19 & 2,442 & 1,043 & 1,399 \\
\hline 10 & 2,027 & 0,621 & 1,406 & $-1,0$ & 1,0 & 20 & 2,446 & 1,047 & 1,399 \\
\hline$\Sigma$ & 13,120 & 13,104 & 0,016 & 0,0 & 126,0 & $\Sigma$ & 17,431 & 17,430 & 0,001 \\
\hline
\end{tabular}

Tab. 1 Merané hodnoty, prevýšenia a opravy

$$
\bar{h}_{1}=-1,405 \mathrm{~m} \quad \begin{aligned}
\bar{h}_{2} & =-1,4015 \mathrm{~m} \quad s=0,0037 \mathrm{~m} \\
\left|\bar{h}_{1}-\bar{h}_{2}\right| & <2,5 . s
\end{aligned}
$$

V riešenej úlohe $\left|\bar{h}_{1}-\bar{h}_{2}\right|=0,004 \mathrm{~m}$ a to je menej ako 2,5.s =0,009m.

\subsection{Nivelačný prístroj Geo Fennell}

Údaje získané z merania NP Geo Fennell, vypočítané prevýšenia, priemerné prevýšenia a opravy sa nachádzajú v tab. $2[1,2]$.

\begin{tabular}{|c|c|c|c|c|c|c|c|c|c|}
\hline 1 & 2 & 3 & 4 & 5 & 6 & 7 & 8 & 9 & 10 \\
$j$ & $\begin{array}{c}x_{A j} \\
{[\mathrm{~m}]}\end{array}$ & $\begin{array}{c}x_{B j} \\
{[\mathrm{~m}]}\end{array}$ & $\begin{array}{c}h_{j} \\
{[\mathrm{~m}]}\end{array}$ & $\begin{array}{c}v_{j} \\
{[\mathrm{~mm}]}\end{array}$ & $\begin{array}{c}v^{2} \\
{\left[\mathrm{~mm}{ }^{2}\right]}\end{array}$ & $j$ & $\begin{array}{c}x_{A j} \\
{[\mathrm{~m}]}\end{array}$ & $\begin{array}{c}x_{B j} \\
{[\mathrm{~m}]}\end{array}$ & $\begin{array}{c}h_{j} \\
{[\mathrm{~m}]}\end{array}$ \\
\hline 1 & 0,500 & 1,904 & $-1,404$ & 4,6 & 21,16 & 11 & 0,962 & 2,365 & $-1,403$ \\
\hline 2 & 0,607 & 2,013 & $-1,406$ & 2,6 & 6,76 & 12 & 0,968 & 2,370 & $-1,402$ \\
\hline 3 & 0,606 & 2,020 & $-1,414$ & $-5,4$ & 29,16 & 13 & 0,978 & 2,381 & $-1,403$ \\
\hline 4 & 0,613 & 2,028 & $-1,415$ & $-6,4$ & 40,96 & 14 & 0,988 & 2,387 & $-1,399$ \\
\hline 5 & 0,596 & 2,001 & $-1,405$ & 3,6 & 12,96 & 15 & 0,993 & 2,394 & $-1,401$ \\
\hline 6 & 2,035 & 0,629 & 1,406 & 2,6 & 6,76 & 16 & 2,390 & 0,988 & 1,402 \\
\hline 7 & 2,041 & 0,630 & 1,411 & $-2,4$ & 5,76 & 17 & 2,387 & 0,986 & 1,401 \\
\hline 8 & 2,038 & 0,628 & 1,410 & $-1,4$ & 1,96 & 18 & 2,381 & 0,979 & 1,402 \\
\hline 9 & 2,048 & 0,641 & 1,407 & 1,6 & 2,56 & 19 & 2,384 & 0,982 & 1,402 \\
\hline 10 & 2,048 & 0,640 & 1,408 & 0,6 & 0,36 & 20 & 2,385 & 0,983 & 1,402 \\
\hline$\Sigma$ & 13,132 & 13,134 & $-0,002$ & 0,0 & 128,4 & $\Sigma$ & 16,816 & 16,815 & 0,001 \\
\hline
\end{tabular}

Tab. 2 Merané hodnoty, prevýšenia a opravy

$$
\begin{array}{lll}
\bar{h}_{1}=-1,4086 \mathrm{~m} & \bar{h}_{2}=-1,4017 \mathrm{~m} & s=0,0038 \mathrm{~m} \\
& \left|\bar{h}_{1}-\bar{h}_{2}\right|<2,5 . s
\end{array}
$$

V riešenej úlohe $\left|\bar{h}_{1}-\bar{h}_{2}\right|=0,007 \mathrm{~m}$ a to je menej ako 2,5.s =0,009m.

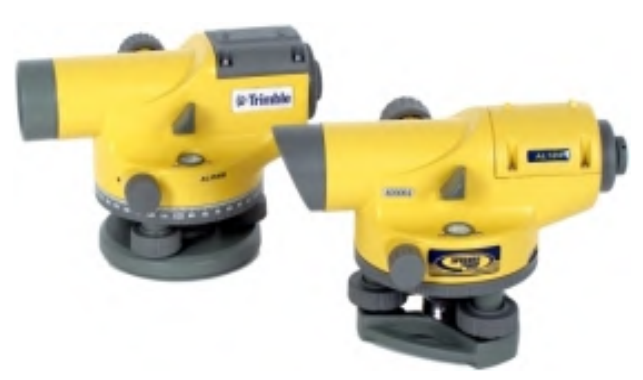

Obr. 5 Nivelačný prístroj Spectra AL100/AL200 [2]

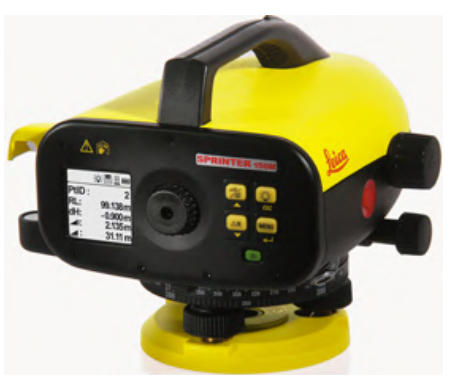

Obr. 5 Nivelačný prístroj Leica Sprinter 150 [2] 


\subsection{Nivelačný prístroj Spectra AL224}

Údaje získané z merania prístrojom Spectra AL224, a nachádzajú v tab. 3 [1, 2].

\begin{tabular}{|c|c|c|c|c|c|c|c|c|c|}
\hline 1 & 2 & 3 & 4 & 5 & 6 & 7 & 8 & 9 & 10 \\
$j$ & $\begin{array}{c}x_{A j} \\
{[\mathrm{~m}]}\end{array}$ & $\begin{array}{c}x_{B j} \\
{[\mathrm{~m}]}\end{array}$ & $\begin{array}{c}h_{j} \\
{[\mathrm{~m}]}\end{array}$ & $\begin{array}{c}v_{j} \\
{[\mathrm{~mm}]}\end{array}$ & $\begin{array}{c}v^{2}{ }_{j} \\
{\left[\mathrm{~mm}^{2}\right]}\end{array}$ & $\begin{array}{c}j \\
x_{A j} \\
{[\mathrm{~m}]}\end{array}$ & $\begin{array}{c}x_{B j} \\
{[\mathrm{~m}]}\end{array}$ & $\begin{array}{c}h_{j} \\
{[\mathrm{~m}]}\end{array}$ \\
\hline 1 & 0,536 & 1,807 & $-1,271$ & 0,2 & 0,04 & 11 & 1,081 & 2,354 & $-1,273$ \\
\hline 2 & 0,588 & 1,859 & $-1,271$ & 0,2 & 0,04 & 12 & 1,093 & 2,367 & $-1,274$ \\
\hline 3 & 0,597 & 1,867 & $-1,270$ & $-0,8$ & 0,64 & 13 & 1,108 & 2,381 & $-1,273$ \\
\hline 4 & 0,590 & 1,860 & $-1,270$ & $-0,8$ & 0,64 & 14 & 1,114 & 2,388 & $-1,274$ \\
\hline 5 & 0,593 & 1,864 & $-1,271$ & 0,2 & 0,04 & 15 & 1,111 & 2,383 & $-1,272$ \\
\hline 6 & 1,912 & 0,643 & 1,269 & 1,8 & 3,24 & 16 & 2,384 & 1,111 & 1,273 \\
\hline 7 & 1,912 & 0,640 & 1,272 & $-1,2$ & 1,44 & 17 & 2,361 & 1,088 & 1,273 \\
\hline 8 & 1,893 & 0,622 & 1,271 & 0,2 & 0,04 & 18 & 2,375 & 1,101 & 1,274 \\
\hline 9 & 1,921 & 0,650 & 1,271 & 0,2 & 0,04 & 19 & 2,368 & 1,096 & 1,272 \\
\hline 10 & 1,914 & 0,642 & 1,272 & $-1,2$ & 1,44 & 20 & 2,371 & 1,098 & 1,273 \\
\hline$\Sigma$ & 12,456 & 12,454 & 0,002 & 0,0 & 7,60 & $\Sigma$ & 17,366 & 17,367 & $-0,001$ \\
\hline
\end{tabular}

Tab. 3 Merané hodnoty, prevýšenia a opravy

$$
\begin{array}{ll}
\bar{h}_{1}=-1,2708 \mathrm{~m} & \bar{h}_{2}=-1,2731 \mathrm{~m} \quad s=0,001 \mathrm{~m} \\
& \left|\bar{h}_{1}-\bar{h}_{2}\right|<2,5 . s
\end{array}
$$

V riešenej úlohe $\left|\bar{h}_{1}-\bar{h}_{2}\right|=0,002 \mathrm{~m}$ a to je menej ako $2,5 . s=0,0025 \mathrm{~m}$.

\subsection{Nivelačný prístroj Leica Sprinter 150}

Údaje získané z merania prístrojom NP Leica Sprinter 150, ako aj vypočítané prevýšenia, priemerné

\begin{tabular}{|c|c|c|c|c|c|c|c|c|c|}
\hline$j$ & $\begin{array}{c}2 \\
x_{A j} \\
{[\mathrm{~m}]}\end{array}$ & $\begin{array}{c}3 \\
x_{B j} \\
{[\mathrm{~m}]}\end{array}$ & $\begin{array}{l}4 \\
h_{j} \\
{[\mathrm{~m}]}\end{array}$ & $\begin{array}{c}5 \\
v_{j} \\
{[\mathrm{~mm}]}\end{array}$ & $\begin{array}{r}6 \\
v_{j}^{2} \\
{\left[\mathrm{~mm}^{2}\right]}\end{array}$ & 7 & $\begin{array}{c}8 \\
x_{A j} \\
{[\mathrm{~m}]}\end{array}$ & $\begin{array}{c}9 \\
x_{B j} \\
{[\mathrm{~m}}\end{array}$ & $\begin{array}{l}10 \\
h_{j} \\
{[\mathrm{~m}]}\end{array}$ \\
\hline 1 & 0,588 & 1,861 & $-1,273$ & 0,6 & 0,36 & 11 & 1,091 & 2,364 & $-1,273$ \\
\hline 2 & 0,664 & 1,937 & $-1,273$ & 0,6 & 0,36 & 12 & 1,077 & 2,351 & $-1,274$ \\
\hline 3 & 0,687 & 1,960 & $-1,273$ & 0,6 & 0,36 & 13 & 1,085 & 2,360 & $-1,275$ \\
\hline 4 & 0,670 & 1,943 & $-1,273$ & 0,6 & 0,36 & 14 & 1,099 & 2,372 & $-1,273$ \\
\hline 5 & 0,676 & 1,948 & $-1,272$ & $-0,4$ & 0,16 & 15 & 1,110 & 2,384 & $-1,274$ \\
\hline 6 & 1,931 & 0,659 & 1,272 & $-0,4$ & 0,16 & 16 & 2,369 & 1,096 & 1,273 \\
\hline 7 & 1,913 & 0,642 & 1,271 & $-1,4$ & 1,96 & 17 & 2,368 & 1,095 & 1,273 \\
\hline 8 & 1,908 & 0,635 & 1,273 & 0,6 & 0,36 & 18 & 2,361 & 1,088 & 1,273 \\
\hline 9 & 1,905 & 0,632 & 1,273 & 0,6 & 0,36 & 19 & 2,364 & 1,091 & 1,273 \\
\hline 10 & 1,914 & 0,643 & 1,271 & $-1,4$ & 1,96 & 20 & 2,359 & 1,086 & 1,273 \\
\hline$\Sigma$ & 12,856 & 12,860 & $-0,004$ & 0,0 & 6,40 & $\Sigma$ & 17,283 & 17,287 & $-0,004$ \\
\hline
\end{tabular}
prevýšenia a opravy sa nachádzajú v tab. 4 [1,2].

Tab. 4 Merané hodnoty, prevýšenia a opravy

$$
\begin{array}{ll}
\bar{h}_{1}=-1,2724 \mathrm{~m} & \bar{h}_{2}=-1,2734 \mathrm{~m} \quad s=0,0008 \mathrm{~m} \\
& \left|\bar{h}_{1}-\bar{h}_{2}\right|<2,5 . s
\end{array}
$$

V riešenej úlohe $\left|\bar{h}_{1}-\bar{h}_{2}\right|=0,001 \mathrm{~m}$ a to je menej ako $2,5 . s=0,002 \mathrm{~m}$. 


\section{ZÁVER}

Technické normy a predpisy majú svoju nezastupitel’nú úlohu na medzinárodnej i na národnej úrovni Ich používanie, ale i preberanie a tvorba sú neodmyslitel'nou a nevyhnutnou zložkou v procese technickej realizácie akéhokol'vek výrobku, tovaru i služby. Takouto službou i tovarom je stavebná činnost' i geodetické práce na stavbe. Používanie technických noriem i ich tvorba sa stáva nevyhnutnou súčast'ou stavebnej i geodetickej praxe a umožňujú skvalitnit' výsledný produkt - stavbu.

Výsledkom kontroly a testovania podl’a STN ISO 17123 -2 je konštatovanie, že kontrolované prístroje (Sokkia C40, Geo Fennell NO.10, Spectra AL100 a Leica Sprinter 150) testované na základe postupu podl'a predmetnej normy a príslušnej testovacej štatistiky (zjednodušená metodika testovania) vyhoveli daným požiadavkám na meranie pre potreby v stavebníctve a môžu byt' plne využívané pre požadované úlohy.

Článok bol spracovaný ako súčast’ projektu VEGA, reg. číslo projektu 1/0133/14 Vedeckej grantovej agentúry MŠ SR „Detekcia plošných a diskrétnych posunov nestabilných území na báze nízko nákladovej fotogrametrie a satelitných technológii"“.

\section{Použitá literatúra}

[1] JEŽKO, J.: Testovanie nivelačných prístrojov podl'a medzinárodnej normy STN ISO 17123-2. In: Aktuálne problémy geodézie, inžinierskej geodézie a fotogrametrie. Vedecko-odborný seminár s medzinárodnou účast'ou. Katedra geodézie, Bratislava, SR, 2011, ISBN 978-80-2273501-8, nestr.

[2] MERVOVÁ, D.: Testovanie nivelačných prístrojov podl'a STN ISO 17123-2. Bakalárska práca, 2010, Katedra geodézie, Bratislava, 38s. + 15 príloh.

[3] STN ISO 17123-2: 2005 Optika a optické prístroje - Postupy na testovanie geodetických prístrojov. 2. čast': Nivelačné prístroje.

[4] STN ISO 17123-5: 2005 Optika a optické prístroje - Postupy na testovanie geodetických prístrojov. 5 čast: Elektronické tachymetre.

[5] STN ISO 17123-3: 2001 Optika a optické prístroje - Postupy na testovanie geodetických prístrojov. 3. čast': Teodolity. 